\title{
Improving patient flow: setting up of an ambulatory care unit in Nevill Hall Hospital using the CORE role of the chief registrar
}

\author{
Authors: S Akhtar, M Brouns, D Wales and C Ward
}

\section{Introduction}

Ambulatory emergency care is an emerging streamlined model for managing emergency patients presenting to hospital who would otherwise be admitted. ${ }^{1}$ These radical patientflow models have emerged in response to the continuing unprecedented rise in the number of emergency hospital attendances and subsequent admissions. The chief registrar, due to working on the front line, is centrally positioned to identify issues, promote collaboration and adopt examples of innovative practice. Nevill Hall Hospital (NHH) is a district general hospital with 165 adult medicine beds situated in Abergavenny, East Wales. It provides inpatient/outpatient care. However, it did not have an Ambulatory Care Unit (ACU) and this is where my project began.

\section{Aim}

Reduce the waiting time for medical patients to be seen by a consultant by $50 \%$ ( 6 hours) over a six-month period.

\section{Methods}

Prior to ACU, all GP medical and surgical referrals were assessed in the Emergency Assessment Unit (EAU). This consisted of 6 trolleys and a waiting area. EAU has 20 beds with an average of 30 medical admissions.

It was long recognised that medical patients presenting to EAU received sub-standard care with up to $40 \%$ waiting longer than the Royal College of Physicians (RCP) defined 14-hour target for consultant review. ${ }^{2}$

A key part of my chief registrar role was to examine and improve the waiting times for EAU Medical patients. The first step was opening an ACU using the RCP's overarching principle: treat all emergency patients as ambulatory until proven otherwise. ${ }^{1}$

Authors: Departments of Acute and Respiratory Medicine, Nevill Hall Hospital, Aneurin Bevan University Health Board, Abergavenny, Wales.
Table 1. Using the CORE chief registrar framework

to positively and effectively influence change.

Adapted from the Future Hospital's 11 Principles of

Care $^{3}$

Collaborative MDT working

I am part of the ACU group, in which a comprehensive multidisciplinary team meets to discuss issues; I ensure that the trainees experiences and views of ACU are discussed.

Organisational change

I visited sites across Wales with established ACU units, which enabled me to view and encourage adopting of good practise for our unit.

Reflective processes

I was able to reflect, discuss and evaluate the process with the network of chief registrars, which helped to ensure timely progression and enabled the overcoming of obstacles and sharing of innovative ideas.

Effective timely patient centred care

I am currently organising a patient questionnaire to ensure co-production of future development of the unit.

The ACU opened in late November 2016, it is a simple twotrolley unit with a waiting area and a consultant-delivered service, but with currently limited opening hours.

\section{Results}

Early data reveals appropriate patient selection as reflected by the high percentage discharge rate of greater than $80 \%$. However, the impact on waiting times has been more variable with an overall reduction to 5.05 hours to discharge from 5.2 , but this data does not include the waiting time of nonambulatory patients.

\section{Conclusion}

The CORE framework is useful in ensuring the Future Hospital's key principles of care are an integral part of 


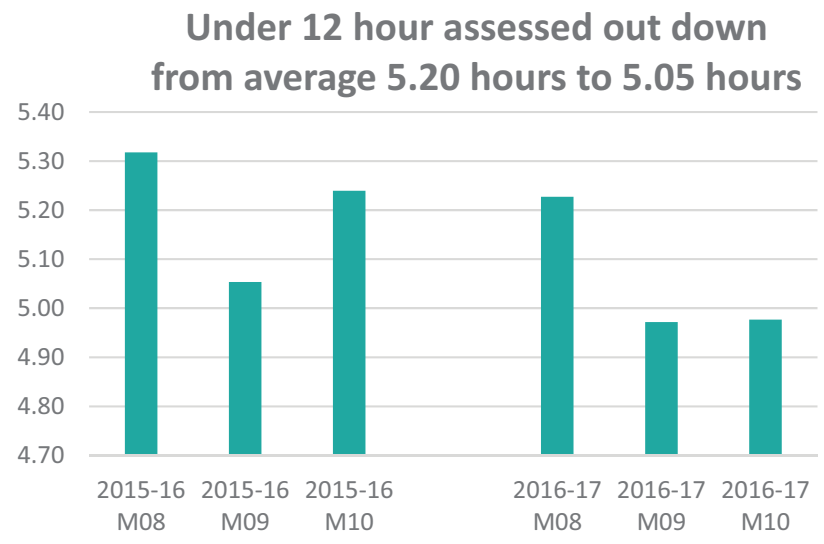

Fig 1. Comparison of waiting times pre and post setting up the ACU.

innovative change. The chief registrar is uniquely positioned to lead and champion change, working both at the front-line and with senior clinicians/managers. Early data reveals that patients are being seen more efficiently, with significantly reduced waiting times, and increased appropriate discharges, resulting in an overall positive patient experience. However, significant work remains, with project phase two aiming to improve waiting times for non-ambulatory patients.

\section{References}

1 Royal College of Physicians. Acute Care Toolkit 10: Ambulatory emergency care. London: RCP, 2014. www.rcplondon.ac.uk/guidelinespolicy/acute-care-toolkit-10-ambulatory-emergency-care

2 Royal College of Physicians. Acute Care Toolkit 4: Delivering a 12 hour, 7 day consultant presence on the acute medical unit. London: RCP, 2015. www.rcplondon.ac.uk/guidelines-policy/acute-caretoolkit-4-delivering-12-hour-7-day-consultant-presence-acutemedical-unit

3 Royal College of Physicians. Future hospital: caring for medical patients. A report from the Future Hospital Commission. London: RCP, 2013. www.rcplondon.ac.uk/projects/outputs/future-hospitalcommission 